\title{
Marineros en tierra y políticos de la mar. Gestión biológica de recursos versus gestión social de pescadores ${ }^{1}$
}

\author{
Carlos Coppel Hidalgo \\ Universidad de Santiago de Compostela
}

\begin{abstract}
Un principio de biología jurídica, confirmado por la experiencia de todos los siglos, declara cómo la realidad es anterior y superior a la ley [...] cuando la ley se ha vaciado en troqueles distintos y existe incongruencia entre ella y las manifestaciones de la vida para quienes está dada, y no coinciden al superponerse como coinciden el calco con su original, semejante ley no se cumple...
\end{abstract}

JOAQUíN COSTA

\section{INTRODUCCIÓN}

El objetivo de este trabajo es abordar un problema que está afectando a todo el sector pesquero de bajura gallego, a través de la posibilidad de ejemplificación que nos ofrece el caso concreto del puerto y la población pesquera de Riveira. El tema a tratar está relacionado con la regulación de los recursos pesqueros y las normativas específicamente elaboradas por las instituciones responsables en asuntos pesqueros en la comunidad autónoma; esto es, la Xunta de Galicia a través de la Consellería de Pesca, Marisqueo y Acuicultura. Más especialmente aquellas que afectan en concreto a los pescadores que dedican su actividad a la explotación del pulpo y de la nécora con el arte de la nasa. Estos entes públicos se plantean su objetivo de la preservación y gestión de los recursos pesqueros de la plataforma costera gallega, regulando el esfuerzo pesquero por medio de la reglamentación de las artes que inciden sobre esos recursos. De tal modo

1 Este trabajo, a pesar de que por diversas circunstancias no se llegó a presentar, se elaboró en el contexto del VIII Congreso de Antropología celebrado en Santiago de Compostela en septiembre de 1999. 
que para gestionar éstos, dentro de esta reglamentación, se dirige la normativa a la misma ordenación de las técnicas de pesca, lo que afecta al modo de vida y al estilo de trabajo de los pescadores.

Vamos a centrarnos en aquellos aspectos más conflictivos y de mayor repercusión en las estrategias económicas de los pescadores implicados en el desarrollo de la Ley de pesca de Galicia (Ley 6/1993 de 11 de Mayo): esto es, el Decreto 424/1993 de 17 de diciembre y la Orden 9 de abril de 1997, donde en la práctica el hecho administrativo ordena la actividad pesquera por medio de la regulación de artes de pesca y sus posibilidades de alternancia. Esta normativa ha creado un problema social en el sector pesquero artesanal en toda Galicia, porque los pescadores se sienten perjudicados en su aplicación; ya que, desde su punto de vista, supone un bloqueo administrativo respecto a su posibilidad de cambiar de arte, a voluntad.

Nuestra intención, al plantear el problema, apunta sobre todo a poner de manifiesto la capacidad de respuesta y la coherencia de las alternativas de los pescadores, sin que necesariamente haya que adherirse a ellas, ante el conflicto generado por las medidas de la administración. Implícitamente, asimismo, queda planteado a lo largo del texto (partiendo de la misma cita inicial de Costa) que el éxito de cualquier sistema de gestión de recursos pesqueros radica no sólo en el tipo de medidas que se aplican, sino en el grado de aceptación que éstas obtienen entre los administrados. La cogestión, es decir la participación de los interesados en la gestación de las regulaciones, crea las mejores expectativas para su cumplimiento. La simple consulta no evita, como es el caso, que la misma normativa genere estrategias adaptativas o económicas de los pescadores al margen de la ley (Cf. Alegret 1999).

\section{El CONTEXTO PESQUERO DEL PUERTO Y LA FLOTA DE RIVEIRA}

El puerto de la pequeña ciudad de Riveira, situada en la provincia de A Coruña, viene siendo habitualmente considerado como el primero de bajura de España, e incluso como uno de los más importantes en este ámbito de Europa. A través de su lonja se comercializa un gran volumen de descargas de pescado en fresco, y una gran variedad de especies, que se traducen en un alto volumen en pesetas para un puerto de estas características. Las capturas comercializadas representan tanto especies de alto valor económico en cantidades discretas (pescadilla, rape, cigala, pulpo, etc.) como especies de bajo precio en cantidades muy considerables (especialmente lirio y jurel, que en esta lonja obtienen precios muy compe- 
titivos). En un ranking de las lonjas gallegas aparecido recientemente en los medios de comunicación, la de Riveira ocupaba un quinto puesto (kgs. y ptas.) en 1998, detrás de la de Vigo, A Coruña, Celeiro y Burela ( $L a$ Voz de Galicia, 21-2-99). Sin embargo, la importancia de su lonja no es resultado exclusivo de las descargas y ventas de su propia flota, sino que también embarcaciones de otros muchos puertos de pesca de litoral del entorno geográfico acostumbran a vender con regularidad sus capturas en el puerto de Riveira.

Si nos ceñimos, no obstante, a la flota específica de Riveira, nos encontramos con un puerto heterogéneo y diversificado, de modo que el conjunto del esfuerzo pesquero lo realizan varias flotillas. Así tenemos flotas especializadas como la del arrastre de fondo de litoral, constituida por 48 embarcaciones, distribuidas en dos modalidades de pesca: el arrastre a la "baca" (pescado variado) y, sobre todo, a la "pareja" (lirio y pescadilla); aunque algunas de las "bacas" (de mayor tecnología, tonelaje y potencia de arrastre) se están orientando últimamente hacia la pesca más especializada del jurel, en simultaneidad y alternancia con el arrastre diverso, para lo cual llevan a bordo de la embarcación dos aparejos: el clásico o bentónico, y el denominado "semipelágico" de mayor dimensión y abertura vertical, pero de menor contacto con el fondo, como el de la "pareja". En su conjunto los barcos que forman la flota del arrastre son los de mayor tamaño y potencia del puerto de Riveira, en lo que se refiere a la pesca de litoral.

Otra flota especializada de Riveira es la del cerco, que cuenta con 10 embarcaciones con una media de cincuenta toneladas (8 de ellas proceden del cercano puerto de Aguiño); pero está complementada de forma invariable y sistemática, en descargas y ventas en la lonja, por las flotas de Cambados y A Illa de Arousa. Las especies sobre las que concentran su esfuerzo pesquero son las habituales del cerco: jurel, sardina, xouba o sardinilla, etc.

Por otra parte, también cuenta el puerto de Riveira con una flota altamente especializada, aunque en este caso en la pesca de altura: se trata de los barcos del palangre que faenan en el banco canario sahariano. Está constituida por 65 embarcaciones equipadas con alta tecnología para la pesca de la merluza en aquellas aguas. Sus puertos habituales de desembarque son Vigo y Algeciras, pues sólo en muy contadas ocasiones y en muy pequeñas cantidades lo hacen en Riveira.

Por último, tiene asimismo una flota más masiva y artesanal que a lo largo del ciclo anual aplica la diversificación como estrategia; es decir, que esta flota no se caracteriza por la utilización de un arte específico, sino que son varias las artes que emplea de forma alternativa (multiartes). Pre- 
cisamente por ello, es a esta flotilla a la que las normativas citadas afectan más negativamente, es decir, a la menos capitalizada de los sectores que componen la flota de Riveira. Está compuesta por unas trescientas embarcaciones con variado tamaño, potencia y tripulación: sus tripulaciones oscilan entre uno y cinco ocupantes. En conclusión, la normativa afectaría a más de quinientos pescadores.

El ciclo anual de pesca, en síntesis, comienza por el marisqueo (siempre a flote), que entre octubre y febrero ocupa a un sector importante de esta flota en la recolección de recursos como la almeja, vieira y ostra, con artes de arrastre manejadas manualmente (rastro de vara) o arrastradas por la popa (rastro de vieira y ostra). El periodo real de explotación abarca desde octubre a diciembre, a pesar de que la veda de la almeja esté abierta hasta febrero y las zonas de libre marisqueo hasta abril. En función de ciertos factores como puede ser la rentabilidad de los bancos, por los precios, el hecho de que las embarcaciones de mayor tonelaje únicamente puedan participar en la recolección de vieira, ostra (con menor período de explotación) o zonas de libre marisqueo, etc., hace que ya algunas embarcaciones simultaneen durante estas fechas esta actividad marisquera con otro tipo de faenas pesqueras (sobre todo, artes de enmalle y nasas, dirigidas especialmente a la nécora).

En cierto modo, hay una relación entre el tamaño de las embarcaciones y las estrategias económicas de los pescadores de Riveira. Las embarcaciones pequeñas, dornas y planeadoras con motor fuera borda, mayoritarias en el puerto, encuentran en la recolección de la almeja, exclusivamente reservada para ellas y procedente de los bancos que tiene en concesión la Cofradía, la actividad más rentable de todo el ciclo anual. Después, durante el resto del año desarrollan estrategias de diversificación, alternando y simultaneando con flexibilidad el arte de la nasa (pulpo, nécora y camarón), las artes de enmalle (betas y miños), el palangrillo (congrio) y la liña. Las embarcaciones medianas (entre 2 y 7 TRB: Tonelaje de Registro Bruto) orientan sus estrategias económicas hacia el libre marisqueo, la vieira y la ostra en los arenales de la concesión administrativa de la Cofradía, diversificando estas actividades con las nasas, el palangrillo, o bien alternando entre ellas las artes de enmalle, principalmente betas y miños; aunque también trasmallos y raeiras, para capturar especies como faneca, pescadilla, salmonete, centollas, chopos, pintos, rayas, maragotas, etc. Las embarcaciones mayores (entre 8 y 12 TRB) han dirigido su actividad de forma intensiva a la captura del pulpo con la nasa; aunque algunas de ellas cambian en la primavera y el verano este arte por el del palangre del congrio, otras lo alternan con la nasa fanequeira (en extinción) y, aún alguna, con las artes de enmalle y el marisqueo (vieira y ostra). 
En general, el arte de la nasa ha ido relegando paulatinamente en Riveira a un lugar secundario a otros aparejos. La nasa que se utiliza es cilíndrica y cerrada, excepto por el embudo que entra la presa. Este arte puede, potencialmente, capturar a tres especies simultáneamente: pulpo, nécora y camarón; por tanto, se trata de un aparejo poco selectivo. Como veremos, parte del conflicto generado con los permisos de explotación establecidos por ley tiene que ver con la intención de hacer selectiva la nasa cilíndrica. El espíritu de la normativa pretende regular cada uno de estos recursos. Sin embargo, tal y como se está empleando la nasa actualmente, tal solución se presenta como tarea imposible, puesto que los dos factores que enumeramos a continuación no hacen al arte más selectiva: a) el cebo no constituye elemento selectivo, puesto que los que se emplean atraen indistintamente a las tres especies; b) los lugares o hábitats en los que se cala habitualmente este arte son prácticamente los mismos para las tres especies. Es decir, que si se quieren regular estos tres recursos, parece obvia la necesidad de realizar algún tipo de transformación en la nasa. De aquí que la administración, para la captura del camarón, exija acoplar a la nasa cilíndrica una boquilla de cinco centímetros que la hace selectiva con relación a esta especie; aunque no resuelve el problema de las otras dos. Un primer intento de solventar esta cuestión se produjo con una regulación emitida hace años, a partir de un diseño de nasa que la administración había realizado con la asesoría de sus biólogos. De armazón abierto y cuadrado, era específica para la captura del pulpo, y dejaba la cilíndrica para la exclusiva captura de la nécora. La regulación recomendaba el uso de esta nasa; pero, dado que no retenía bien la presa, transcurrido un tiempo fue abandonada por los pescadores por inoperante y poco rentable.

Ahora a la vuelta de los años, el problema sigue siendo el mismo y la administración ha intentado por fin darlo por resuelto con el Decreto 424/1993. En función de la naturaleza (hábitos de conducta) de estos recursos (nécora y pulpo) es posible integrar algún criterio de selectividad en el uso de la nasa, de cara a su regulación. Así, el pulpo tiene hábitos alimentarios diurnos, mientras que la nécora se alimenta especialmente durante la noche. De modo que el Decreto fija a partir de este criterio, de manera excluyente los lances diurnos para el pulpo y los lances nocturnos para la nécora. Aunque, como veremos, este elemento selectivo introducido genera también problemas considerables.

Por otra parte, la administración regula estos recursos estableciendo: a) épocas de veda para la nécora (de febrero a junio) y pulpo (reciente, por paro biológico durante el mes de junio); b) limitando el número de nasas por embarcación; c) peso mínimo para el pulpo (750 gramos) y 
tamaño mínimo para la nécora $(5 \mathrm{~cm}$.); el camarón no está regulado, si exceptuamos la obligatoriedad de la boquilla y del lance nocturno en su captura; no se establecen topes máximos de captura para ninguna de las especies.

\section{El PROBLEMA BÁSICO EN EL MOMENTO DE REGULAR LA ALTERNANCIA Y LA POSIBILIDAD DE TOPES DE CAPTURA}

A excepción de los bancos de bivalvos tradicionales, regulados por la Cofradía de Pescadores, nos encontramos en un ámbito pesquero en el que todos los caladeros que frecuentan estas embarcaciones se encuentran con los recursos en estado de sobreexplotación. Es decir, que los recursos son escasos y el número de productores es alto. Esta situación ha generado que tanto la administración como las cofradías vean la necesidad de una regulación, con la finalidad de que el nivel de rentabilidad de la explotación de estos recursos permita una vida digna a los pescadores.

Sin embargo, esta demanda (en la que administración y pescadores están de acuerdo) entra en conflicto con éstos, ante la solución específica aportada por aquélla: en tanto que la regulación ofrecida por medio de la normativa limita la capacidad operativa de los productores menores y artesanales, y reduce sensiblemente sus beneficios. Antes de su promulgación, la libertad de establecer estrategias de diversificación entre los pescadores era mucho mayor. Ahora con la legislación se produce una constricción legal que incide sobre la misma posibilidad de diversificar su actividad y optimizar su economía; pues únicamente desde los diferentes grados de diversificación o alternancia se entiende que esta actividad pesquera artesanal es rentable.

Ante la específica regulación restrictiva de la administración (personalizada a través del permiso de explotación adjudicado a cada embarcación) en las posibilidades de alternancia de artes, los pescadores alegan que incluso de un año para otro pueden cambiar sus expectativas con respecto a un determinado arte u "oficio", puesto que las circunstancias que lo hacen rentable o sostenible puedan variar y hacerse adversas. Es probable que incluso durante mucho tiempo mantengan una determinada alternancia de artes que les permita "defender" su unidad productiva; pero el medio fortuito al que se enfrentan no admite una actitud uniforme o normativa, sino elástica, ante unas capturas o unas pesquerías inciertas. En las conductas productivas espontáneas de los pescadores la reversibilidad es casi en sí misma una estrategia o un componente fundamental que 
facilita aquella. Así, a una estrategia de intensificación que implique el declive de una pesquería, como la del pulpo en Riveira, es muy razonable que le siga otra de diversificación y alternancia, dentro de un proceso de respuesta mudable y relacionado. De modo que atendiendo a la toma de posición y a la práctica de los productores, se puede concluir de antemano que el "permiso de explotación" que introduce la nueva normativa, como hemos de pormenorizar, en su aplicación práctica parte de un concepto estático de la actividad pesquera artesanal que contrasta con el concepto dinámico, consustancial a las estrategias adaptativas y económicas de los pescadores: actos o respuestas dinámicas y flexibles ante los problemas, incentivos, constricciones y cambios que el entorno ambiental presenta (Galván 1989).

Como consecuencia de las transferencias en materia pesquera del gobierno central a la comunidad autónoma de Galicia, la Xunta elaboró en 1993 la Ley de Pesca (Ley 6/93 de 11 de mayo) a través de la Consellería de Pesca. En su Título II recoge todo lo que trata de la explotación de los recursos marinos de Galicia, y como objetivo general se propone la gestión equilibrada y el provecho económico de estos recursos. Se resalta como objetivo prioritario la regulación del esfuerzo pesquero, hacia un nivel de rendimiento de máximo sostenible. Dentro de estos principios, sin embargo, se afirma que se tendrán también en cuenta las circunstancias económicas y sociales de las personas que participen en la explotación de los recursos, para que las medidas a establecer puedan conseguir el bienestar de las comunidades pesqueras que dependen de ellos.

Dentro del Título II, el capítulo cuatro trata de los permisos de explotación de pesca y marisqueo. Asunto crucial para el tema que queremos exponer, ya que a partir de esta ley la Xunta establece unos permisos que serán expedidos por la Consellería a nombre de la embarcación, en el caso de la pesca y el marisqueo a flote, que cubren legalmente la actividad extractiva de recursos marinos de todos los tripulantes enrolados. Este permiso de explotación será intransferible a terceros, con la única salvedad de que esta transferencia se haga conjuntamente con la embarcación, o a otra embarcación que sustituya a la anterior. Sólo será válido para las zonas en él indicadas y por el plazo de cinco años, renovables por otros cinco hasta un máximo de treinta. El permiso de explotación será expedido específicamente para especies, bancos, artes y grupos de artes determinadas. Estas podrán ser estacionalmente alternantes, pero no se podrán autorizar dos artes o grupos de artes a la vez. Se exige además a los titulares de estos permisos de explotación que faciliten los datos de la actividad que realizan en cada momento. Con estas notas extraídas de la Ley de Pesca nos interesa resaltar que, a partir de estos permisos de explota- 
ción, ya se empieza a limitar la libertad de alternancia de artes que, con anterioridad a la aparición de la inspección pesquera autonómica, existía.

En el tema de nuestro interés, la Ley de Pesca tiene su primer desarrollo efectivo en el Decreto 424/1993, donde se aprueba la regulación de la actividad pesquera y de las artes y aparejos de pesca permisibles en Galicia. En él se considera necesaria en sí misma la regulación de las pesquerías, argumentando que estas artes no pueden proliferar de forma incontrolada ya que tienen influencia directa en el esfuerzo de pesca ejercido en los caladeros gallegos. De modo que, en síntesis, el Decreto relaciona las artes autorizadas en Galicia; aunque especificando las características, medidas y número que debe poseer cada una de ellas dentro de la normativa, así como su relación con el TRB de la embarcación, etc. Establece también con carácter general un descanso semanal de 48 horas, un consiguiente ejercicio de pesca limitado a cinco días, y fija la distinción entre horarios nocturnos y diurnos en las actividades pesqueras, con especificación posterior detallada para las diversas modalidades de pesca.

Por otra parte, reconoce el carácter alternante de la actividad extractiva en la comunidad autónoma, por lo que acepta que una misma embarcación podrá obtener autorización para varias modalidades de pesca. Sin embargo, esta alternancia será establecida unilateralmente por la Consellería de Pesca: de cómo se llevó a la práctica de modo provisional esta disposición hablaremos a continuación, pues es cuestión relevante en la materia que nos ocupa.

4. El ESTADO DE COSAS ANTERIOR AL PERMiSO DE EXPLOTACIÓN Y LAS NUEVAS RESTRICCIONES A LAS ESTRATEGIAS TRADICIONALES DE DIVERSIFICACIÓN PESQUERA

Antes del año 94 los armadores de Riveira tenían obligación de estar inscritos para ejercer su actividad profesional en la Ayudantía de Marina, hoy Capitanía, por medio de un documento que se conoce como rol, o "rolo", en el que se hacía constar los datos de la embarcación, el número y los datos de los marineros enrolados, las artes con las que estaban en cada momento faenando, etc. A esta misma entidad tenían que notificarle obligatoriamente toda modificación que se produjera en el rol, en el sentido indicado. Aunque cada cierto tiempo, independientemente de que se produjeran modificaciones o no, había que renovarlo, no existía ninguna restricción en lo referido a elección de artes de pesca. En la actualidad el rol sigue vigente, y de hecho es el sistema habitual que tienen los armadores de notificar sus permutas de arte o marinería. 
El cambio sustancial que introduce el actual permiso de explotación, con respecto a la situación anterior, radica en que ahora toda actividad marítima que afecte a los recursos marinos debe ser sancionada a su través, de un modo individualizado, tal y como lo hemos descrito más arriba. Las limitaciones que establece en materia de artes para cada embarcación las expresa de manera positiva y excluyente: es decir, que en el permiso deben constar las artes de pesca para las que está autorizada, excluyendo todas aquellas que no consten en él. De antemano también excluye la simultaneidad, por lo que el armador que quiere cambiar de arte, dentro de las que tiene autorizadas la embarcación, tiene que notificarlo cada vez en Capitanía por medio de la presentación del rol.

En principio, para establecer inicial y provisionalmente las artes de pesca autorizadas que debían figurar en el permiso de explotación de cada embarcación, la Consellería solicitó fotocopias de los roles de varios años atrás de cada una de ellas (dos o tres años), donde se contemplaban las artes para las que estaban "despachando" habitualmente en los últimos tiempos. A partir de esa información se determinó el contenido de cada uno de los permisos, limitando desde ese momento las posibilidades de alternancia a las que más o menos allí figuraban, considerando que si con aquellas artes habían podido desarrollar su actividad productiva en los últimos años, bien podían continuar en la misma línea de trabajo en lo sucesivo. Así, de manera diferencial, unas embarcaciones quedaron súbitamente con más posibilidades de alternancia y otras con menos: en función de las diversas estrategias productivas de los pescadores y el consecuente número de artes que figuraban en cada rol durante los años inmediatamente anteriores a la elaboración del permiso de explotación.

Esta forma de entender la actividad productiva de los pescadores de bajura y sus estrategias económicas, sobre todo las que inciden en las posibilidades de diversificación o alternancia de artes, tiene una contestación discordante e inmediata por parte de aquéllos en Riveira, pues no entienden que se limiten sus alternativas de pesca. Por lo tanto, el efecto más lesivo de esta normativa sobre las estrategias de diversificación es que las restringe hasta una situación límite: la administración actúa como si los recursos no se vieran sometidos a alteraciones en el tamaño de sus poblaciones. De manera que un pescador que viene "despachando" con asiduidad para el pulpo, si se da el caso de que este recurso disminuya como en realidad está ocurriendo en Riveira, se le hace insostenible, económicamente hablando, la actividad productiva. Este pescador tendría que amarrar el barco, ante la imposibilidad de recurrir a otras artes que podía emplear en el desarrollo de su actividad hasta ese momento. 
En lo que se refiere a las combinaciones para la alternancia de artes que contemplaba cada permiso de explotación la casuística era muy variada y dispar; pero, en general, estos permisos dejaban muy estrechas posibilidades de diversificación. En el caso específico de Riveira, lo más frecuente era que un alto porcentaje de los permisos de explotación no superara las tres artes autorizadas, dándose también casos no necesariamente aislados de embarcaciones con tan sólo una o dos artes en su permiso. Como consecuencia muchos pescadores se vieron obligados, por las actuaciones emanadas de la misma normativa, a generar estrategias al margen de la ley para hacer viable su unidad productiva. Otros acabaron abandonando definitivamente la actividad artesanal para enrolarse en el palangre de altura, o en el arrastre de litoral.

De modo aparentemente popular, "ante a reiterada demanda do sector", como se reconoce en el mismo texto de la Orden de 9 de abril de 1997, la Consellería de Pesca se decide posteriormente a regular de manera oficial la necesaria alternancia de artes para embarcaciones que pesquen en aguas de la comunidad autónoma. Parte igualmente del hecho indudable del sometimiento de los recursos pesqueros a un sobreesfuerzo, deduciendo que la alternancia debe conjugar la necesaria limitación del esfuerzo sobre los recursos marinos con la posibilidad de pescar todo el año, de modo que se pueda garantizar la rentabilidad económica de las embarcaciones. Reconoce formalmente la peculiaridad de nuestras costas, los usos y costumbres y la profesionalidad de los armadores, así como el derecho que éstos tienen a elegir las artes a que van a dedicar sus embarcaciones. Pero este derecho debe venir limitado por los antecedentes de las artes empleadas hasta hoy por cada embarcación, y por el esfuerzo pesquero potencial existente en la actualidad en cada zona. Entiende por "alternancia" la posibilidad que tiene cada embarcación de pescar con las diferentes artes incluidas en el permiso de explotación, pero prohibe la simultaneidad de artes un mismo día, así como la tenencia a bordo de más artes que la de uso. Para paliar el problema suscitado, autoriza un número máximo de cinco artes en el permiso de explotación: por lo cual los armadores tendrán bien que renunciar al exceso (se dieron situaciones en las que algunas embarcaciones superaban las cinco artes en su permiso) o bien solicitar el defecto. Sin embargo, en su artículo $9 .^{\circ}$ la citada orden establece como límite máximo, a la hora de autorizarse las nuevas artes en el permiso de explotación, el esfuerzo potencial existente en cada zona costera; aunque con carácter general, el número de artes por zonas no podrá incrementarse por encima del $20 \%$ de las ya existentes. Cada cinco años con su renovación el armador podrá solicitar el cambio de artes, siempre con las limitaciones que impone el artículo 9. 
A pesar de esta última normativa, que aparentemente abría la posibilidad de cinco artes en el permiso de explotación, la situación cambió poco en Riveira. En primer lugar, porque la orden no se hizo efectiva, ya que de las solicitudes presentadas no se resolvió ninguna, si se exceptúan las de los armadores que renunciaron a artes a extinguir (consideradas destructivas, por lo que no se contempla la concesión de nuevos permisos), o las de algunos otros que consiguieron demostrar documentalmente que con anterioridad habían "despachado" para el arte que reclamaban. En segundo lugar, aunque se hubiera llegado a producir finalmente esa ampliación, sólo muy parcialmente se solventaría el problema generado, ya que los pescadores consideran que la forma de entender la Consellería el tema de las cinco artes es aún muy restrictiva, en tanto que es impropia su manera de tomar como artes distintas algunas que estrictamente no lo son. Efectivamente, al pretender el anterior Decreto integrar criterios selectivos en la clasificación de las modalidades de pesca, daba ocasión para que en el permiso se contabilizaran algunas artes en función de las diversas especies objeto de su extracción. Por ejemplo, en el caso del marisqueo: la almeja, la vieira y la ostra, constaban en él como tres posibilidades de alternancia. Bien es verdad que se trata de dos artes o dos tipos de rastro diferentes (rastro de vara para la almeja, y rastro remolcado para la vieira y la ostra), pero los pescadores los engloban en un mismo "oficio", al que dedican además un termino medio de tres meses en el ciclo anual. Otro caso es el de la nasa cilíndrica que, siendo sustancialmente el mismo arte, el Decreto la considera como tres diferentes: nasa del pulpo, nasa de la nécora (en función del criterio diurno/ nocturno ya aludido) y nasa del camarón, en razón de la boquilla acoplada de cinco centímetros. Esta última eventualidad dio lugar a que los permisos de explotación, con variaciones diversas, pudieran contemplar unas especies, excluyendo las otras.

\section{LA CONFIGURACIÓN ESPECÍfICA DEL PROBLEMA EN RIVEIRA}

Para hacer más inteligibles el problema y los argumentos de los pescadores, mejor será continuar el relato de los acontecimientos que en la actualidad se suceden. Veamos primero el de la veda del pulpo, que por vez primera se inicia en el año 1998 y constituye el momento más álgido del conflicto en Riveira. Esta veda, propuesta para junio de ese año, no se vio bien en Riveira por dos razones. La primera, porque eran muchas las embarcaciones que se encontraban en las siguientes situaciones: 1) únicamente tenían reconocido en su permiso de explotación la nasa del 
pulpo, 2) la del pulpo y la de nécora, 3) la del pulpo y marisqueo, 4) la del pulpo, la de la nécora y marisqueo. Teniendo en cuenta que el marisqueo y la nécora en esa fecha estaban a su vez vedados, todas estas embarcaciones durante la veda o el paro del pulpo tendrían que quedar necesariamente amarradas en el puerto. La segunda razón estaba relacionada con el hecho de que la Consellería atendiera en su decisión final -la de establecer la veda o el paro del pulpo para junio- más bien a los intereses particulares de los puertos y las cofradías situadas más al norte (de Porto do Son hacia arriba: Fisterra, Camariñas, Malpica, Cariño, etc.), favorables a ella en la época del verano: ya que por su configuración pesquera trabajan en invierno intensamente con las nasas, mientras que en verano cambian invariablemente al cerquillo ( $x o u b a$, sardina...).

La alternativa que proponía, y aún propone a la veda del pulpo, la Cofradía de Riveira (junto a las de Pobra do Caramiñal, Cabo de Cruz, Rianxo y Bueu) se resume en los siguientes puntos: 1) el peso no debe estar nunca por debajo del kilo (frente a los 750 gramos reglados), y todo lo que se capture inferior a esa talla debe ser devuelto al mar; 2) el número o tope de nasas por embarcación no debe superar las quinientas (es difícil obtener una productividad suficiente con menos nasas, para tripulaciones que rondan los cinco hombres) o, en todo caso, las trescientas cincuenta que marca la normativa, siempre que este tope fuera inflexible para todos los puertos; 3) si el número de nasas es discutible, lo que es indiscutible es que las nasas tienen que volver a tierra, porque además de otra manera serían incontrolables. Este último punto, que también recoge la normativa vigente, fue muy discutido por las cofradías del norte que reivindicaban la posibilidad de dejar las nasas fondeadas en el mar. Las propuestas diferentes, y el trance en que ponía la veda a la flota de bajura de Riveira, no fueron tenidos en cuenta y la veda se aprobó. Los enfrentamientos con la administración y entre las mismas cofradías fueron muy duros, como lo expresaron en su momento los medios de comunicación.

Es de destacar el hecho de que la proposición popular de Riveira no haga más que recoger preceptos dictados por la misma Consellería, e incluso endurecerlos. Es en casos como este donde cobra sentido el hecho de que los mismos pescadores reprochen a la administración su incapacidad de hacer cumplir su prolija normativa, en tanto que desde su punto de vista sería más eficaz proponer menos normas, pero que éstas realmente las cumplieran todos los pescadores.

Ante la inminente aplicación de la veda del pulpo y las protestas de los pescadores de Riveira, la Consellería a finales de abril ofreció en exclusiva a aquellos que se encuentran en las situaciones más arriba enu- 
meradas, que durante ese mes soliciten otra arte de pesca para poder faenar durante ese breve periodo. Esto se brinda a la espera de la resolución de la autorización de las cinco artes que ya solicitaron. Las asambleas en la Cofradía fueron tensas y airadas ante este ofrecimiento, pues los pescadores no veían que ésta fuera una solución razonable al problema que se les presentaba. En primer lugar, porque esa alternancia provisional (sólo un mes) no les compensaba de los gastos que les podía ocasionar la adquisición de un aparejo que luego iba a quedar obsoleto. En segundo lugar, porque pensaban que la veda o la paralización de la pesca del pulpo debía ser subvencionada, como ocurre con el cerco y el arrastre cuando se dan similares circunstancias. En tercer lugar, porque consideraban que era la administración la responsable de la situación creada, al limitar tan inflexiblemente la alternancia de artes, y además ser incapaz de ofrecer una salida estable y no provisional al problema.

\section{LA VALORACIÓN DEL "SENTIDO PRÁCTICO" Y DEL CONOCIMIENTO DE LOS PESCADORES DE SU MEDIO: AUSENCIA DE SU PARTICIPACIÓN EN LA RESOLUCIÓN DEL CONFLICTO}

Es evidente que el problema de la veda del pulpo está íntimamente relacionado en Riveira con las posibilidades de alternancia de artes, que limitan los actuales permisos de explotación. El caso del pulpo es ya bastante expresivo de la vivencia de callejón sin salida que tienen hoy los pescadores, ya que en esta ocasión el bloqueo administrativo rompe la única alternativa viable a su declive como pesquería, o a su veda, como paliativo consecuente: la posibilidad de diversificación. Esta situación se daba, como hemos podido comprobar, con pescadores que tenían incluso tres posibilidades de alternancia $\mathrm{y}$, sin embargo, ninguna alternativa.

De la normativa no rechazan, con relación a la alternancia, por ejemplo, que no puedan combinar simultáneamente dos artes en el mismo día; aceptando, pues, no llevar en la embarcación más que un aparejo, a pesar de que sufren un agravio comparativo con algunos barcos del arrastre, para los que no existe cortapisa legal en este sentido. Igualmente aceptan la partición selectiva que la norma impone sobre el uso de las artes, en lances diurnos y nocturnos. Incluso en el arte de la nasa, donde la restricción selectiva atiende en realidad a las especies objeto de la captura. Por supuesto, admiten la prohibición de simultanear el día y la noche en estos casos, pues de hecho nunca trabajan jornadas tan intensivas y agotadoras. Sin embargo, mantienen su discrepancia con respecto a su fundamento, en tanto que intenta restringir su misma forma de trabajo. A 
la última orden dictada, y a la concepción de las artes que subyace, proponen como alternativa otra manera de concebir las cinco "artes" o los cinco "oficios" (el concepto de oficio siempre es plural para los marineros de bajura) que un productor podría alternar. Así engloban almeja, ostra y vieira en un único "oficio": pues se trata de un mismo marisco bivalvo, objeto de la misma actividad de marisqueo. Otro "oficio" sería, dentro de la misma proposición, el que abarca marisco crustáceo más cefalópodo (nasa de la nécora, camarón y pulpo) ya que se utiliza la misma nasa. Otro tercer oficio más, todas aquellas artes que sean de enmalle (betas, miños...), siempre que reúnan las embarcaciones todas las condiciones de tonelaje que marca la normativa. Por último todavía otro, que contemplaría el palangrillo y la liña como artes de anzuelo; y aún quedaría seguramente abierta otra alternativa, hasta cubrir los cinco.

Bien es verdad que esta propuesta reúne también artes diferentes en un único "oficio"; pero porque a conciencia intenta recoger con amplitud las alternativas más viables para que los productores se repartan equitativamente por la plataforma pesquera. Pues la verdadera divergencia en este apartado, entre administración y pescadores, está en la forma de intentar resolver el dilema que plantea el declive de los recursos pesqueros. La primera contempla la proliferación excesiva del número de artes como causa importante del sobreesfuerzo ejercido sobre los escasos recursos, confundiendo quizás su número con las posibilidades de alternancia. Los segundos ven la restricción del número de artes en los permisos de explotación como una de las razones fundamentales de que haya tanta sobrecarga sobre algunas especies: por lo que argumentan que existiendo alternativas —es decir, posibilidades de alternancia y diversificación- los productores, sin dejar por ello de respetar las vedas, se reparten más entre las diversas artes: marisqueo, nasas, aparejos, etc., evitando la incidencia excesiva sobre unas pocas especies. En este sentido, interpretan que la restricción de artes en el permiso de explotación supone también un bloqueo administrativo a la salida más natural del problema. También piensan que esta forma suya de enfocar el problema puede tener un efecto positivo sobre la comercialización de las capturas, porque las cantidades descargadas en la lonja de las diversas especies estarán más repartidas, y con ello no se satura el mercado, los precios no bajan, y con menos kilos se pueden obtener idénticos o mayores beneficios.

El razonamiento que esgrimen los pescadores, en torno a su capacidad de cambiar de arte como forma de distribuir su esfuerzo pesquero sobre la diversidad de los recursos, es aplicable igualmente al caso de la nasa del pulpo y la nécora. Consideran que la limitación administrativa en los permisos no ha hecho más que contribuir a una intensificación 
excluyente sobre ambas especies; dado que en Riveira, aunque hay embarcaciones que poseen permiso para las dos especies, es mucho más frecuente que quien lo tiene para la una no lo tenga para la otra. De este modo arguyen que resultaría más positivo si se reparten en alternancia los productores entre ambas especies, aplicando el criterio selectivo que ofrece la jornada diurna y nocturna, que ir todos juntos al pulpo o todos juntos a la nécora, como está ocurriendo; siempre que este reparto se integre también dentro de la posibilidad de mayor diversificación que ofrecen otras artes.

Es recurrente entre los pescadores tomar en su discurso, como modelo y analogía, la experiencia de cogestión de la Cofradía (Agrupación de Mariscadores) en la concesión administrativa de los bancos de la almeja. Poniéndolo en relación con lo expuesto anteriormente, relatan que hace años decidieron abrir en tres partes esos bancos: a principio de temporada el primero, después el segundo y luego el tercero; el resultado fue un desastre, los bancos tuvieron una merma importante en los siguientes años. Desde entonces, siempre que el marisco tenga el tamaño adecuado, abren toda la concesión, en la que va a trabajar la misma gente, el mismo tiempo, pero repartidos, sin sobrecargar ninguna zona. En la explotación de estos arenales ellos mismos pagan la vigilancia para evitar el furtivismo, abren y cierran zonas en función del tamaño de la almeja, y mantienen los topes de recolección, no sólo en razón del cuidado, sino de la rentabilidad y la comercialización. Esta es óptima, ya que consiguen una productividad media de venta diaria de dos mil kilos en lonja, que debido a su tamaño, dureza y calidad es adquirida por importantes empresas conserveras gallegas que llegan a pagar por ella hasta 4.000 pesetas el kilo.

Siguiendo con la analogía, para la próxima veda del pulpo que se prevé de dos meses, sin prescindir de las medidas que propusieron como alternativa a la primera, consideran que sería asimismo imprescindible fijar unos topes de captura, porque de otra forma la experiencia del año anterior les enseñó que en poco tiempo se trae todo el pulpo para tierra a bajo precio, y los que se benefician son lo frigoríficos (compradores mayoritarios del pulpo en la lonja), pues es una especie que admite congelación. Saben que en el caso del pulpo (aplicable a la nécora) la tarea a acometer va a ser mucho más compleja que en el de la almeja; pero transcurrido un tiempo, piensan que, manteniendo cupos y tamaños, con pocos kilos pueden obtener mayores beneficios sin poner a la especie en peligro. En esta dirección, consideran asimismo que el apoyo de la Xunta sería imprescindible. Por otra parte, la idea que apunta a introducir cupos de captura para esta flota más artesanal (poco capitalizada y de bajo tonelaje), es decir formas de regulación directa, se contrapone novedosa- 
mente al modelo de regulación indirecta elegida e impuesta por la administración para este ámbito pesquero (Cf. Alegret 1999: 110).

Lo que muestra la visión paradigmática que tienen los pescadores del tema de la almeja, es que la forma compartida entre administración y cofradías en la gestión de los recursos se manifiesta mucho más eficaz que las regulaciones donde, como en la presente, no se encuentran directamente comprometidos los pescadores, tanto en su elaboración como en su aplicación y control posterior. En el caso presente la Xunta no ha intentado tanto imponer como recabar un consenso, a través de consultas posteriores. La dificultad ha estribado en que, en la elaboración del contenido de las regulaciones, no se ha tenido en cuenta ni los problemas a los que se enfrentan los pescadores ni la forma en que los conciben. De aquí que tanto los pescadores como sus organizaciones hayan percibido como arbitrarias, y elaboradas desde la lejanía de los despachos, las medidas sobre las posibilidades de combinar las artes, hasta desembocar en el conflicto.

Por último, la veda de 1999 constituye una fuente de incertidumbre para los pescadores de Riveira, en tanto que la administración se demora en dar respuesta a las solicitudes de alternancia de artes. Necesitan saber con cierta antelación las alternancias que van a autorizar porque les apremia tener adquiridos esos aparejos, y no pueden hacer la inversión sin saber de antemano si ese desembolso se corresponderá con lo que se va a otorgar en los permisos. De modo que el conflicto se reaviva, sobre todo, porque en los puertos del norte (Camariñas, Malpica...) la orden de alternancia de artes ya está en vías de aplicación. La Cofradía de Riveira, en consecuencia, está presionando a diversos entes públicos, entre los que se encuentra el mismo alcalde de la ciudad. Temen que, si la alternancia de artes no se resuelve este año, la situación del anterior se repita y que parte de la flota de bajura quede parada sin posibilidades de pesca en ese periodo.

\section{CONCLUSIONES}

En definitiva, los pescadores de Riveira vienen planteando que por una serie de circunstancias, a las que la normativa específica sobre las posibilidades de alternancia de artes no es ajena, gran parte de la flota de bajura se ve empujada a desarrollar básicamente su actividad incidiendo sobre unas pocas especies que, además, en el presente están en declive. Ven, por otra parte, que las opciones que contemplan como la solución más adecuada al problema son, de nuevo, bloqueadas por las mismas normativas que pretenden resolverlas. No encuentran tampoco en sus contactos 
con la administración una vía de diálogo que les permita hacerse entender por ésta.

Veamos brevemente algunos de los factores que consideramos que están interviniendo, directa o indirectamente, en este conflicto. Es evidente que el problema tiene una clara connotación política, tanto porque la normativa generada por la administración produce una insatisfacción en los productores que ha conducido a un proceso de inestabilidad o conflictividad social, como porque han intervenido en el desarrollo de los acontecimientos instancias políticas y sectores con diferentes intereses y afinidades.

Asimismo, sería de destacar que de manera recurrente esta flota artesanal -no la industrial, altura o la de litoral con mayor inversión de capital - es la menos favorecida y la más perjudicada, en todos los sentidos, por las actuaciones de la administración (atención, subvenciones, leyes, etc.). Más específicamente, en la elaboración y en las actuaciones de la normativa que nos ocupa, no se tiene en cuenta o se desconoce en su transcendencia que la supervivencia y los rendimientos económicos de esta flota pasan necesariamente por las estrategias de diversificación. Coartar esta flexibilidad con políticas pesqueras rígidas pone en peligro la supervivencia futura de estas unidades de producción.

Esta falta de atención, o este desconocimiento, se debe a que la administración de pesquerías, creada por estos organismos públicos está esencialmente orientada hacia una regulación deformada de la actividad pesquera, en la que priman los criterios biológicos a priori sobre los socioeconómicos y culturales. De forma que la política pesquera que se practica tiende a generar medidas conservacionistas enfocadas a regular el esfuerzo pesquero y preservar los recursos marinos, sin pararse demasiado a considerar la repercusión o los problemas que estas medidas pueden acarrear sobre las poblaciones de pescadores, sus unidades productivas y sus usos locales. Desde este enfoque unilateral y cuantitativo, tras declaraciones meramente formales sobre la vida y el bienestar de las comunidades pesqueras, se pasa por alto la posibilidad real de incorporar las informaciones cualitativas (propias de los estudios dirigidos al conocimiento empírico, de primera mano) sobre la realidad más inmediata, e incluso diferencial, de estas comunidades. Esta carencia hace incomprensibles al legislador las formas de trabajo y la lógica de las costumbres locales del pescador - atribuyéndole la causa del declive pesquero, además-, y, junto a la falta de su consenso, hace devenir en ineficaces las normas así generadas.

En consecuencia, este déficit en el conocimiento inmediato de las diversas poblaciones pesqueras obstaculiza la toma en consideración de la especificidad de cada una de ellas, a la hora de elaborar las normativas que les afectan. No se puede olvidar el temperamento, la conducta y la 
configuración diferencial que las distingue; no todas son equivalentes, ni tienen los mismos problemas o intereses. La homogeneización o unificación de las medidas legales para una población diversa puede ser reductora, cuando no equívoca, errada o injusta. Así pues, sin dejar de aceptar una necesaria legislación marco, sería asimismo adecuado y eficaz atender a las características específicas de cada una de las unidades de población. De aquí que avanzar hacia formas compartidas de gestión y responsabilidad entre la administración y las organizaciones de pescadores se muestre, en estos casos, como la mejor manera de consolidar la explotación sostenible de los recursos, ya que tienen de antemano la aceptación de los administrados, con cuya experiencia se cuenta como garantía suplementaria de éxito posterior.

\section{DOCUMENTACIÓN Y BIBLIOGRAFÍA CITADA}

LEI 6/1993, do 11 de maio; DOGA n. ${ }^{\circ} 101$, 31-5-93 (Ley de Pesca de Galicia).

DECRETO 424/1993, do 17 de decembro; DOGA n. ${ }^{\circ} 13,20-1-94$.

DECRETO 369/1994, do 2 decembro; DOGA n. 242 , 19-12-94.

ORDE do 9 de abril de 1997; DOGA n. ${ }^{\circ}$ 90, 13-5-97.

TELEFAX: 27-4-1998; De: Director Xeral de Recursos Mariños, A: Patrons Maiores e Presidentes de Organizacións e Asociacións. Pola que se dan instuccións a tódalas confrarías para palia-los efectos que poidan derivarse da posible paralización da captura de polbo en aguas da Comunidade Autónoma de Galicia.

ALEGRET, JUAN LUIS. 1999. "Gestión comunitaria, cogestión y mercado. La evolución histórica de la gestión de la pesca en el mediterráneo español. Actas del VIII Congreso de Antropología (Simposio III: Antropología de la Pesca): 109-123. Santiago de Compostela: AGA.

Costa, JoAQUín. 1981. Derecho consuetudinario y economía popular de España. Zaragoza: Guara editorial.

GalVÁn TUdELA, AlBerTo. 1989. "Estrategias económicas en la pesca artesanal canaria". Jornadas sobre economía y sociología de las comunidades pesqueras: 495-510. Madrid: MAPA.

GARCía Allut, ANTONIO. 1990. "Del libre acceso a la propiedad comunal: el caso de la comunidad pesquera de Muxía (Galicia).. Eres (Antropología) 2: 99-114.

- 1998. "Conocimiento experto y su papel en el diseño de nuevas políticas pesqueras". Coloquio comunidades piscatorias. Revista etnográfica. ISCT, Lisboa (en prensa).

MartíneZ-Veiga, Ubaldo. 1990. Antropología Económica. Barcelona: Icaria.

PASCUAL FERNÁNDEZ, JOSÉ J. 1989. "Antropología marítima y administración de pesquerías". Jornadas sobre economia y sociología de las comunidades pesqueras: 531-592. Madrid: MAPA.

SÁNCHEZ FERNÁNDEZ, JUAN OLIVER. 1992. Ecología y estrategias sociales de los pescadores de Cudillero. Madrid: Siglo XXI. 